\title{
Comparative studies on the flocculation efficiencies of Moringa oleifera (MO), polyacrylamide-grafted gum arabic (GA-g-PAAM) and blended products of MO and PA-g-PAAM
}

\author{
M. B. ALANG ${ }^{*}$, J. T. BARMINAS, B. A. ALIYU, R. USAKU and A. E. SAMUEL \\ Department of Chemistry, Federal University of Technology, PMB 2076 Yola - Nigeria. \\ Federal Institute of Industrial Research (FIIR) Oshodi, Lagos - Nigeria. \\ *Corresponding author, E-mail: alangmibong@agat.net
}

\begin{abstract}
Graft copolymerization of polyacrylamide onto gum arabic was carried out in aqueous medium at room temperature $\left(30{ }^{\circ} \mathrm{C}\right)$ using previously optimized concentrations of initiator (ceric ion) and the monomer (acrylamide). The percentage graft yield was high (70\%) due to optimization of reaction conditions. Reactive blends of Moringa oleifera (MO) and the graft copolymer (GA-g-PAAM) were also synthesized in different ratios of MO to GA-g-PAAM. The blended and unblended graft copolymers and Moringa oleifera were characterized by infrared (IR) spectroscopy. Flocculation capabilities of GA-g-PAAM, the reactive blends (RB), the physical blends (PB) and Moringa oleifera were studied on turbid river water using UV-Visible spectrophotometry at three different wavelengths $(\lambda=400, \lambda=600$ and $\lambda=800 \mathrm{~nm})$ in order to observe the effect of wavelength on flocculation efficiency. The results generally showed that the flocculation efficiency was a function of both flocculation time allowed and the wavelength of UV-radiation used. Hence, the flocculation efficiency was higher for longer flocculation times and longer wavelengths of UV-radiation and vice versa. The flocculation efficiencies obtained after 24 hours at $\lambda=800 \mathrm{~nm}$ followed the order below: MO $(99.61 \%)>$ GA-gPAAM $(94.30 \%)>$ MO \& GA-g-PAAM 3:1 RB $(91.16 \%)>1: 3 \mathrm{RB}(89.58 \%)>1: 1 \mathrm{~PB}(87.07 \%)>1: 1 \mathrm{RB}$ $(82.35 \%)$. The sludge produced by the above water treatment chemicals was small in volume, biodegradable and consequently did not promote environmental degradation. Through chemical derivatization, gum arabic was transformed into a water treatment chemical with more advantages over conventional coagulants.

(C) 2011 International Formulae Group. All rights reserved.
\end{abstract}

Keywords: Sludge, Biodegradable, Environment, Turbid water, Derivatization, Coagulant.

\section{INTRODUCTION}

The problem faced by many developing nations today, especially in Africa is that of getting clean drinking water at a low price (Lilliehöök, 2005), and due to the fact that most surface waters are usually contaminated and require appropriate treatment procedures to rip them of their constituent contaminants. Water treatment procedures have been in existence for centuries. Most of these procedures however are either very cumbersome requiring skilled and intensive labour for the attainment of requisite water quality or the water treatment chemicals are significantly expensive. As a result, these systems cannot be set up at every 
nook and cranny of society; a situation detrimental to the well -being of the rural populace as they are exposed to water polluted with suspended solids, colored substances like micro and macro algae (Dibenedetto, 2011), heavy metals, organic and inorganic substances like phenols, cyanides, sulphides and other soluble substances (Ahmad et al., 2007; Osemeahon et al., 2008) with attendant water borne diseases (Willey et al., 2008). Some of the water treatment procedures and chemicals still leave much to be desired as they seldom accomplish in toto water treatment when used singly. In addition, some of these methods give rise to by-products that pose threats to the environment and consequently the organism. Examples here include the carcinogenic trihalomethanes (THMs) arising from chemical disinfection of water and the alkaline residue produced as a result of sludge disposal from conventional coagulants by incineration.

$$
3 \mathrm{Cl}_{2(g)}+\mathrm{CH}_{4(g)} \rightarrow \underset{\text { Trichloromethane }}{\mathrm{CHCl}_{3(g)}}+3 \mathrm{HCl}_{(g)}
$$

Sludge from conventional coagulants such as alum is significantly nonbiodegradable, thus constituting an environmental nuisance (Gerard and John, 1987). Also when disposed of by incineration, they still dent the environment quality because they give rise to corrosive ash, which raise the $\mathrm{pH}$ of the soil. Due to the numerous problems of inorganic water treatment chemicals, research is more inclined towards the manufacture of organic synthetic and usually polymeric alternatives with limited shortcomings. The general tendency of research and development is to produce effective products affordable to all and sundry. Also advancement in Science and Technology has enabled the production of more effective polymeric materials for various applications by combining natural and synthetic polymeric materials through a technique known as graft copolymerization.
The grafted polymeric product can be possibly blended with other products to further impart desirable characteristics which yields a much more versatile product with enhanced synergistic properties tailored towards the attainment of specific objectives. Relevant works on grafting reactions have been reported in this area of research. These include; the synthesis and chemical linking of polyacrylamide and carboxymethyl cellulose via graft copolymerization and their synergistic effects experimented on targeted applications such as water treatment (Ogbeifun and Okieimen; 2004). Mention was however not made on other sources of polysaccharides such as gum exudates. Osemeahon et al.(2007) produced a blended membrane of sodium alginate and polyacrylamide grafted "konkoli" gum (a natural polymer) with a laudable sorption capacity which can remove some heavy metals from aqueous solutions such as $\mathrm{Fe}^{2+}$, $\mathrm{Pb}^{2+}$ and $\mathrm{Cu}^{2+}$ and thus finds application in remediation of wastewater amongst inter alia. The document did not however give information on the flocculation attributes of the blended product, neither was there any indication on the potential of the product to attenuate or alleviate the microbial and pathogenic load of water systems. It was thus in the light of these predicaments inter alia that this piece of research was undertaken primarily to investigate the synergistic effect of a new product obtainable through graft copolymerization of polyacrylamide onto gum arabic, principally as a flocculant for water treatment. The research proceeded to blend the grafted copolymer with the seed extract of Moringa oleifera plant and then investigated the flocculation properties of the products.

\section{MATERIALS AND METHODS Materials}

Moringa oleifera (MO) seed pods were purchased from farmers in Yola and its environs in Nigeria. Gum Arabic (GA) was 
purchased from Kano city in northern Nigeria. Ceric ammonium nitrate (CAN), acrylamide, acetone, hydroquinone, ethanol, acetic acid, and methanol were purchased from $\mathrm{BDH}$ laboratories and used as supplied without further purification. Raw water samples were obtained from river Benue in Yola town, Adamawa State - Nigeria and at the same suction point as does the Jimeta Water Treatment Plant. Laboratory apparatus were likewise employed in the research including instruments, glass wares, distilled water and detergents.

\section{Preparation of gum arabic}

Gum arabic (grade one Acacia senegal) dried exudates were purchased in powdered form from farmers and weighed then stored at room temperature $\left(30^{\circ} \mathrm{C}\right)$ for subsequent use in graft copolymer synthesis.

Preparation of Moringa oleifera (MO) seeds Matured pods of Moringa oleifera (MO) tree were collected from neighborhood farms and gardens in Yola where the plant grows in relative abundance. The seed kernels were treated following the procedure outlined by Schwarz (2000) and Abdulkarim et al. (2004). The seeds were removed from dry shells and then crushed to powder using a mortar and pestle. The resulting powder was sieved using a $500 \mu \mathrm{m}$ mesh to screen out coarse particles and the fine powder was packaged in a polyethene bag and kept under dry cool conditions pending usage in the research.

\section{Graft copolymerization of acrylamide and gum arabic}

The unblended grafted co-polymeric product utilized in this segment of research was synthesized using the optimized concentrations of the initiator (ceric ions) and monomer (acrylamide). The synthesis and subsequent purification was done in consonance with the procedure of Tripathy and Singh (2001).

\section{Infrared spectroscopic analysis of the graft copolymer}

In order to understand the mechanism of flocculation inter alia, the IR spectra of the products under investigation were measured. These included the IR spectra of MO, 1:1 reactive blend (RB) of M.O and GA, and the 3:1 RB of M.O. and GA. Powdered samples of products were scanned from $4000 \mathrm{~cm}^{-1}$ to $600 \mathrm{~cm}^{-1}$. The IR spectra were taken with the aid of the Fourier Transform Infrared Spectrophotometer (SHIMADZU FTIR8400S).

\section{Collection of turbid water}

Turbid water used in this research was collected from Yola town in Nigeria and at the same source and at the same suction point as does the Jimeta Water Board. The turbid water was collected near the bank of the river Benue in a 5 liter plastic container and transported to the laboratory where the water was kept at room temperature for later use.

\section{Blending of Moringa. oleifera with grafted copolymeric product}

Two types of blending were employed in the process of investigating the flocculation and synergistic effect of a natural product $\mathrm{MO}$ and the synthetic product (GA-g-PAAMs). These blending types included physical and reactive blending.

\section{Reactive blending}

Reactive blending was conducted by preparing 2\% solutions of mixtures of $\mathrm{MO}$ and GA powder samples in different ratios such as $1: 1,1: 3$ and $3: 1$. For the $1: 1$ ratio of MO and GA, $1 \mathrm{~g}$ of each sample was weighed, mixed and dissolved in $100 \mathrm{ml}$ of distilled water and then the same procedure for graft copolymerization was followed as that of the unblended grafted copolymer alone which is 
the procedure outlined by Tripathy and Singh (2001). Similarly, $0.5 \mathrm{~g}$ and $1.5 \mathrm{~g}$ and also 1.5 $\mathrm{g}$ and $0.5 \mathrm{~g}$ of $\mathrm{MO}$ and GA were mixed to prepare $2 \%$ solutions of the ratios $1: 3$ and $3: 1$ giving different grades of reactive blends. The concentrations of CAN and AM used in the reactive blending were the optimized concentrations and the chemically blended products were synthesized using the same procedure and reaction conditions that were used for the unblended GA-g-PAM.

\section{Flocculation efficiency of GA-g-PAAM, MO and blended products}

The co-polymeric products were then used on raw waters to investigate their ability to clarify the raw waters. Ultra-violet (UV) spectrophotometry was similarly employed to monitor their flocculation abilities through absorbance measurements for wavelengths between $400-800 \mathrm{~nm}$ inclusive. The absorbance measurements were used to compute the flocculation efficiencies of the products under study and thus used to classify the materials. Blending was conducted to study the synergistic effect of a natural flocculant (MO) and a grafted synthetic flocculant (GA-g-PAM).

The absorbance values $\left[A=\log \left(\frac{I_{o}}{I}\right)\right]$ of untreated turbid waters were measured with the aid of a UV spectrophotometer (Spectronic 2D 722 - 2000) prior to treatment with the flocculants. The UVspectrophotometer was calibrated with distilled water (blank determination) and then $0.2 \mathrm{~g}$ of each of the test products was added to $250 \mathrm{ml}$ of untreated waters and the absorbance was followed spectrophotometrically at 10 minutes intervals for 90 minutes. The absorbance values of these treated water samples were then taken after 150 minutes ( 2.5 hours) and then after 24 hours. This was done in order to observe the effect of time on flocculation efficiency. Absorbance measurements were carried out at different wavelengths to also determine the dependence of flocculation efficiency on wavelength of UV radiation. The products whose absorbance values were measured after dissolving $0.2 \mathrm{~g}$ of each in $250 \mathrm{ml}$ beaker included; MO, GA-gPAAM, physically blended M.O and GA-gPAM (1:1), reactive blends of M.O \& GA-gPAM (1:1, 1:3, and 3:1). The flocculation efficiency of each product was calculated using a mathematical formula earlier employed by Hamma'adama (2005):

Flocculation efficiency $=\frac{A_{0}-A_{f}}{A_{0}} \times 100$

Where $A_{o}$ is the absorbance of the raw water sample and $A_{f}$ is the absorbance of the clarified supernatant water. The efficiency of each product to clarify raw water was calculated after 2.5 hours and 24 hours of reaction times and at different wavelengths (400, 600 and $800 \mathrm{~nm}$ ) to depict the dependence of flocculation efficiency on time.

\section{RESULTS AND DISCUSSION}

This piece of research was undertaken primarily to synthesize a grafted copolymeric product using gum arabic and polyacrylamide, blend the graft copolymeric product with Moringa oleifera physically and chemically, and then proceed to evaluate the abilities of these products including MO to clarify turbid waters. The results show that all the tested products possessed significant flocculation abilities. The newly synthesized and blended products have the potential of replacing conventional coagulants as water treatment chemicals due to their synergistic effect, biodegradability and low sludge volume when used (Hocking et al., 2002). These research results are therefore environmentally non-deleterious. Hence the research is in conformity with contemporary technologies which are tailored towards the sustenance of a sane environment such as preventing the degeneration of soil fertility 
(Alamu et al., 2007) or minimization of green house gas emissions (Romeo et al., 2011). The biodegradability of the products is very relevant to the economy of the process (Raju et al., 2008) as extra technology with attendant expenditure shall not be developed to dispose waste. The uniqueness of this research however lies in the fact that the synthesized products are effective in the treatment of water for domestic use and also for treating environmentally harmful industrial effluents.

\section{Graft copolymer and reactive blends synthesis}

Table 1 gives the synthetic details of the optimized grafted product that was characterized and the synthetic details of the reactively blended polymeric products. The percentage yield for each reactive blends followed the order; $70.5 \%$ for product $\mathrm{C}$ (MO \& GA-g-PAAM, 1:3 Reactive Blend) followed by $40 \%$ for product $\mathrm{D}$ (MO \& GA-gPAAM, 3:1 Reactive blend) and then $24 \%$ for product B (MO \& GA-g-PAAM, 1:1 Reactive Blend). From table 1, the undulating percentage yields for the blended products may be due to non - optimization of reaction conditions. Meanwhile for the unblended product, an impressive $85 \%$ yield was obtained probably due to meticulous implementation of the optimized reaction conditions.

\section{Flocculation propensity}

Figure 1 depicts the IR spectra of Moringa oleifera (MO); Figure 2 shows the IR spectra of MO and GA-g-PAAM 1:1 reactive blend while Figure 3 illustrates the IR spectra of MO \&GA-g-PAAM 3:1 reactive blend. The IR spectra of MO contain a broad peak at $3439.19 \mathrm{~cm}^{-1}$ corresponding to the absorption of - $\mathrm{NH}$ groups (Morrison \& Boyd, 2007) from protein components in the natural product. This confirms literature reports that when the crushed seeds of MO are mixed with water, they yield water soluble proteins which carry positive charges probably due to protonation of the amine functional groups. The solution acts as a natural cationic polyelectrolyte during water treatment (Sutherland et al., 1994). The positively charged protein components thus act like magnets attracting the predominantly negatively charged particles such as clay, silk, bacteria and other impurities in water systems thus leading to flocculation (Sutherland et al., 1994). Hence derivatization of gum arabic through graft copolymerization with polyacrylamide gave GA-g-PAAM whose IR spectra had absorption peaks at $2361.91 \mathrm{~cm}^{-1}$ and $3467.78 \mathrm{~cm}^{-1}$ for $-\mathrm{CN}$ and $-\mathrm{NH}$ respectively which are responsible for the flocculation qualities of the grafted polymeric product. The presence or incorporation of these groups into gum arabic thus imparted unprecedented flocculation properties to it which before possessed emulsifying and encapsulating properties in solution (Underwood and Cheetham, 1994). Also, blending the grafted products with Moringa oleifera further enhances the flocculation property of the substances and rips $\mathrm{MO}$ of its foul odour sometimes experienced when used to treat water. Different ratios of blending were carried out to verify the best combination with greatest synergy to affect flocculation. From the flocculation tests, blends with higher proportions of MO were better flocculants due to more protein functional groups which constitute the brain behind flocculation. This difference is seen in figures 5, 6 and 7 respectively. The IR spectra of the reactive blends displayed similar features and had significant flocculation properties as can be observed in Figures 2 and 3.

\section{Flocculation efficiencies}

Table 2 depicts the flocculation efficiencies of six products determined by spectrophotometry. The absorbance of the 
supernatant water of each turbid water sample treated with test product was followed with time and at different wavelengths. From the table of results presented, we can classify the flocculants in order of decreasing flocculating abilities according to data collected after 24 hours at the $800 \mathrm{~nm}$ wavelength as follows; MO > GA-g-PAAM > MO \& GA-g-PAAM 3:1 Reactive blend > MO \& GA-g-PAAM 1:3 Reactive blend > MO \& GA-g-PAAM 1:1 Physical blend > MO \& GA-g-PAAM 1:1 Reactive blend. The flocculation efficiency of $\mathrm{MO}$ is highest probably due its protein rich content which facilitates flocculation through protonation of amine functional groups and subsequent attraction of the predominantly negatively charged colloidal particles in water including bacteria and the trend follows for the rest of the flocculants. Hence the gradients of the flocculation curves for MO are greatest for each wavelength compared to the gradients of the rest of the flocculants and seen in Figure 4. In general, the flocculation efficiencies of the blended products is lower than that of the natural product (MO) and the optimized grafted product (GA-g-PAAM) probably due to non optimization of reactive blending conditions.

Table 1: Synthetic details of blended and unblended products and percentage yield.

\begin{tabular}{|c|c|c|c|c|c|c|}
\hline \multicolumn{2}{|c|}{ Polymeric products } & \multirow{2}{*}{$\begin{array}{l}\begin{array}{l}\text { Mass of } \\
\text { GA }(\mathbf{g})\end{array} \\
2.0\end{array}$} & \multirow{2}{*}{$\begin{array}{l}\text { Mass of } \\
\text { MO (g) }\end{array}$} & \multirow{2}{*}{$\begin{array}{l}\text { Conc. of CAN } \\
\times 10^{-3} \mathrm{M} \\
3.0\end{array}$} & \multirow{2}{*}{$\begin{array}{l}\text { Conc. of AM } \\
\times \mathbf{1 0}^{-2} \mathbf{M} \\
20\end{array}$} & \multirow{2}{*}{$\begin{array}{l}\begin{array}{l}\text { \% Graft } \\
\text { yield }\end{array} \\
85\end{array}$} \\
\hline $\mathbf{A}$ & $\begin{array}{l}\text { Optimized } \\
\text { GA-g-PAAM }\end{array}$ & & & & & \\
\hline $\mathbf{B}$ & $\begin{array}{l}\text { MO\&GA-g- } \\
\text { PAAM } \\
\text { 1:1Reactive } \\
\text { Blend }\end{array}$ & 1.0 & 1.0 & 3.0 & 20 & 24 \\
\hline $\mathbf{C}$ & $\begin{array}{l}\text { MO\&GA-g- } \\
\text { PAAM } \\
\text { 1:3Reactive } \\
\text { Blend }\end{array}$ & 1.5 & 0.5 & 3.0 & 20 & 70.5 \\
\hline D & $\begin{array}{l}\text { MO\&GA-g- } \\
\text { PAAM } \\
\text { 3:1Reactive } \\
\text { Blend }\end{array}$ & 0.5 & 1.5 & 3.0 & 20 & 40.5 \\
\hline
\end{tabular}

Table 2: Dependence of flocculation efficiency on time at $\lambda=800 \mathrm{~nm}$.

\begin{tabular}{lcc}
\hline Flocculant & \multicolumn{2}{c}{ Flocculation efficiency (\%) } \\
\cline { 2 - 3 } & After 2.5 Hours & After 24 Hours \\
\hline Moringa oleifera & 89.76 & 99.61 \\
GA-g-PAAM & 80.38 & 94.30 \\
Reactive Blend (3:1) & 64.92 & 91.16 \\
Reactive Blend (1:3) & 57.99 & 89.58 \\
Physical Blend (1:1) & 41.84 & 87.07 \\
Reactive Blend (1:1) & 35.75 & 82.38 \\
\hline
\end{tabular}




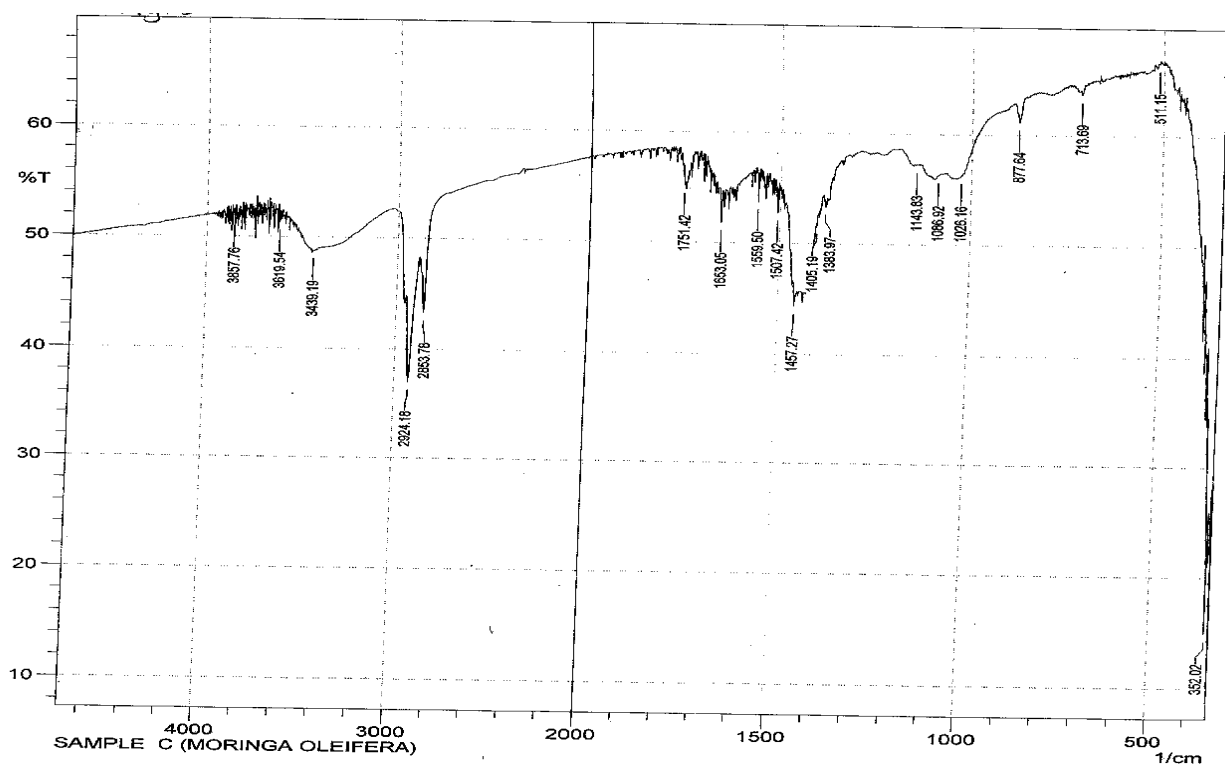

Figure 1: IR spectra of Moringa oleifera.

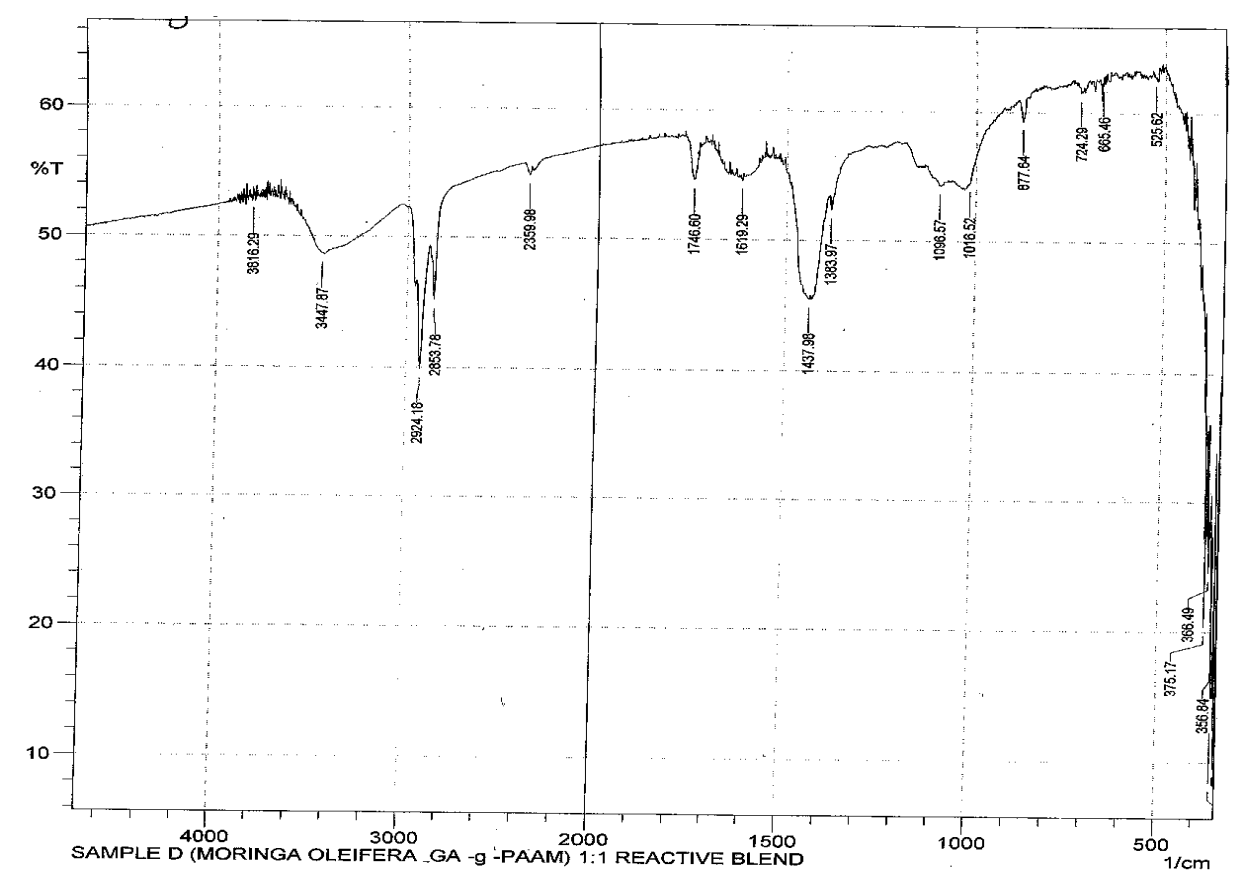
(n...

Figure 2: IR spectra of MO \& GA-g-PAAM(1:1 Reactive blend). 
M. B. ALANG et al. / Int. J. Biol. Chem. Sci. 5(5): 2140-2154, 2011

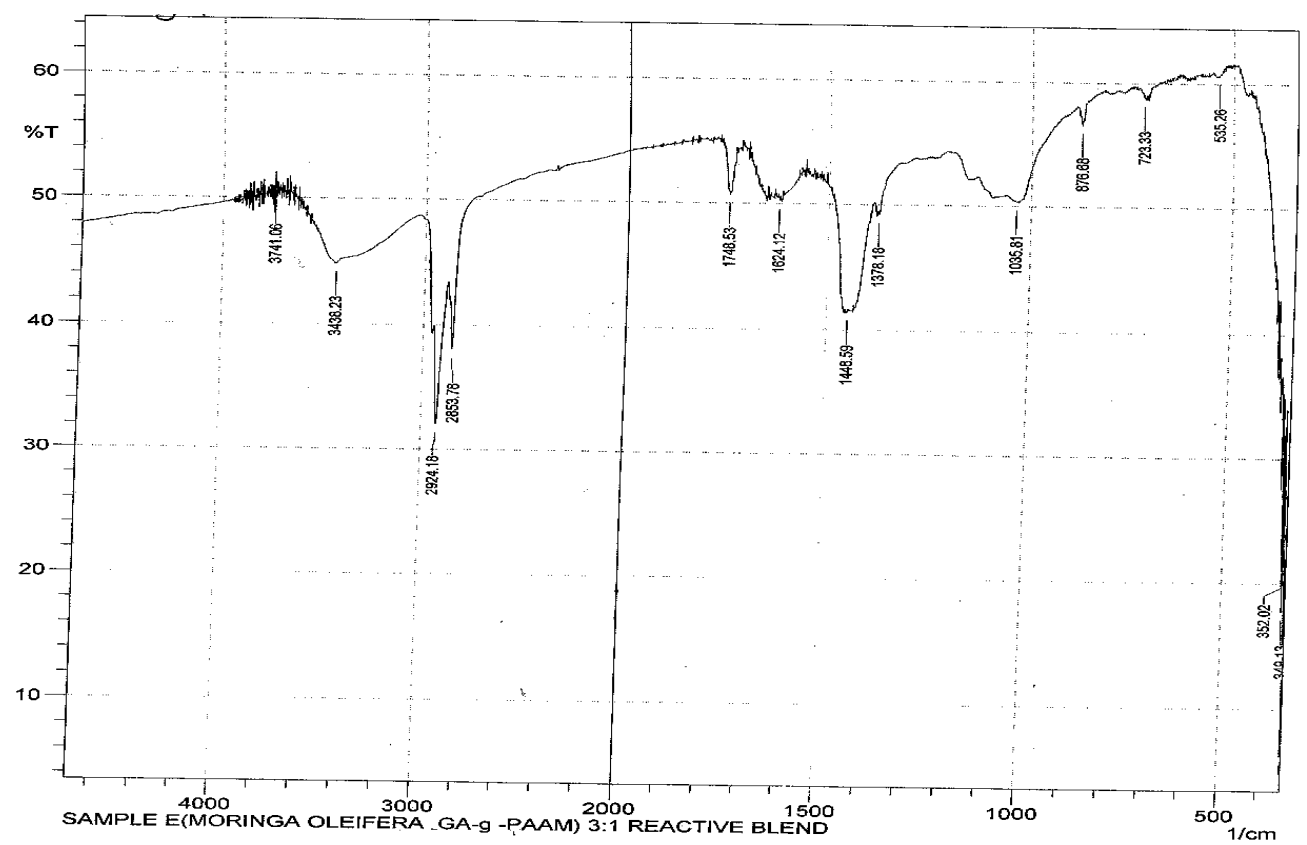

Figure 3: IR spectra of MO \& GA-g-PAAM(3:1 Reactive blend).

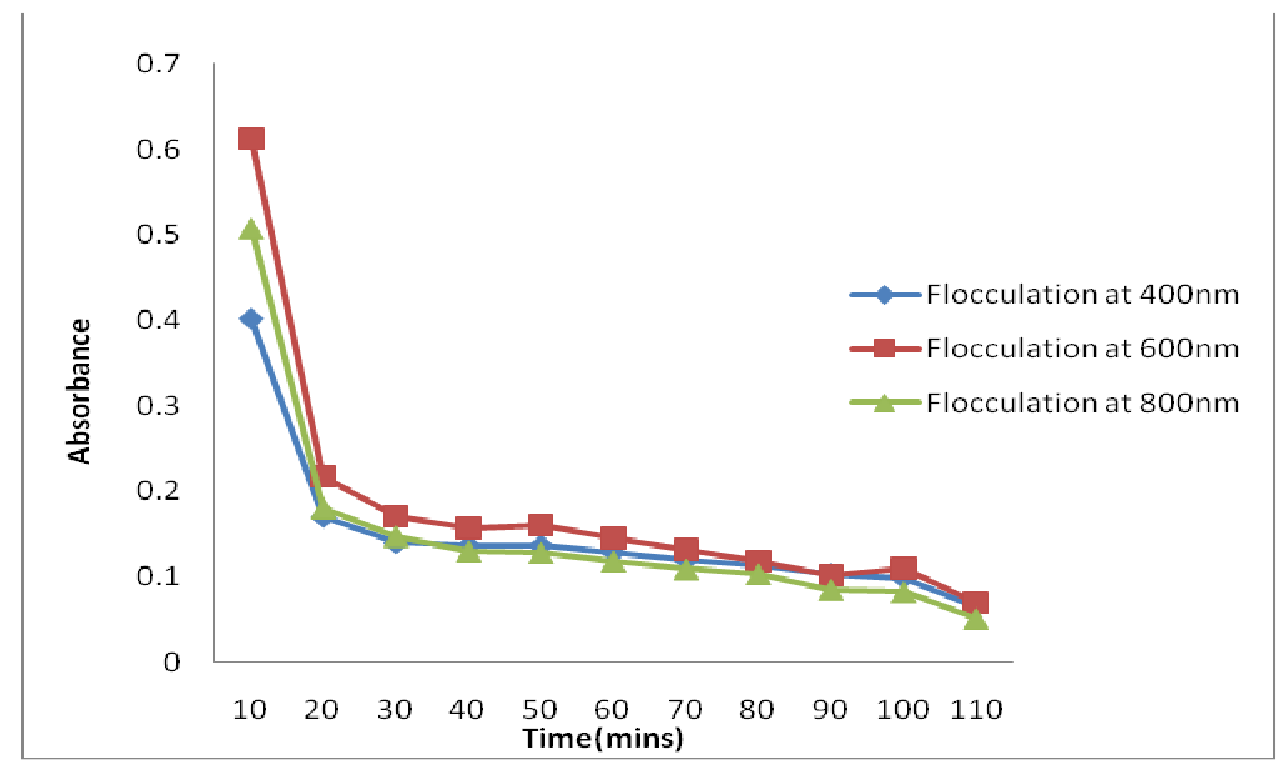

Figure 4: Flocculation profiles for Moringa oleifera at different wavelengths. 


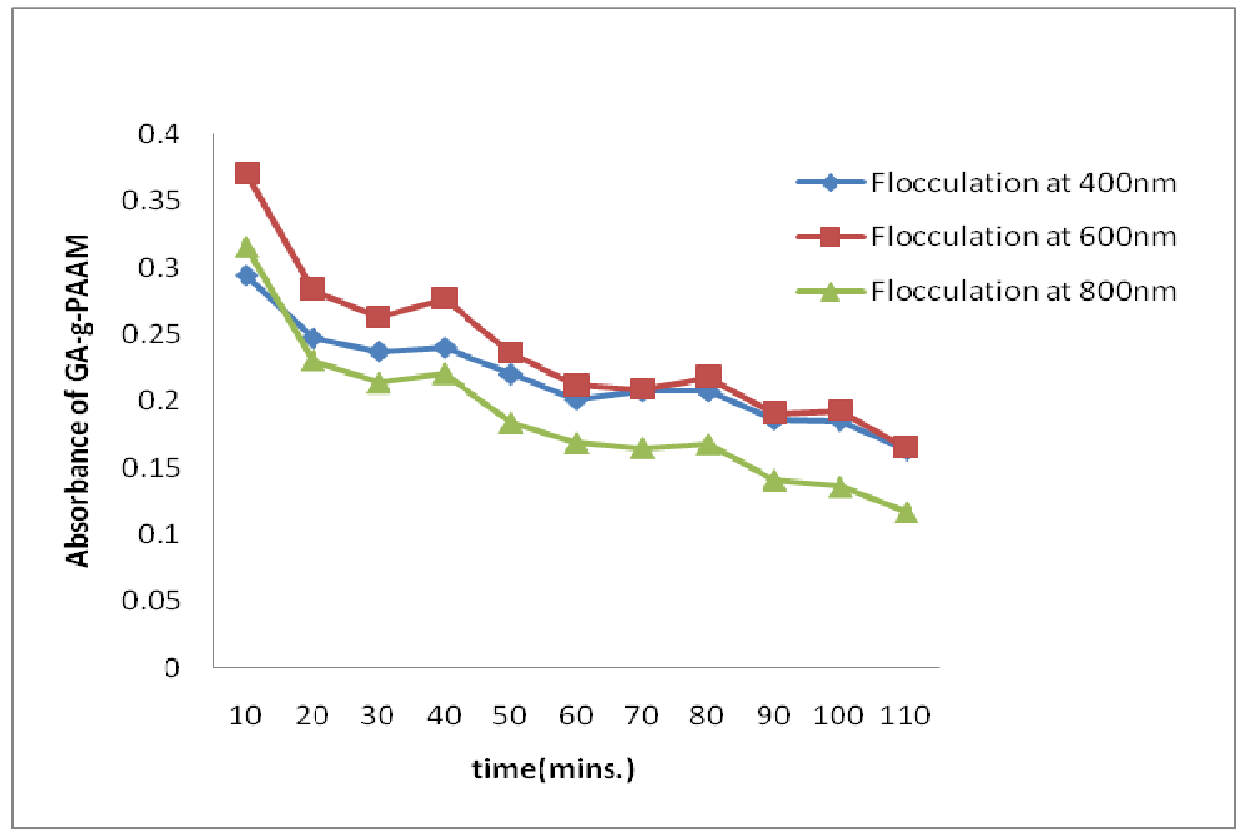

Figure 5: Flocculation profiles of GA-g-PAAM at diferent wavelengths.

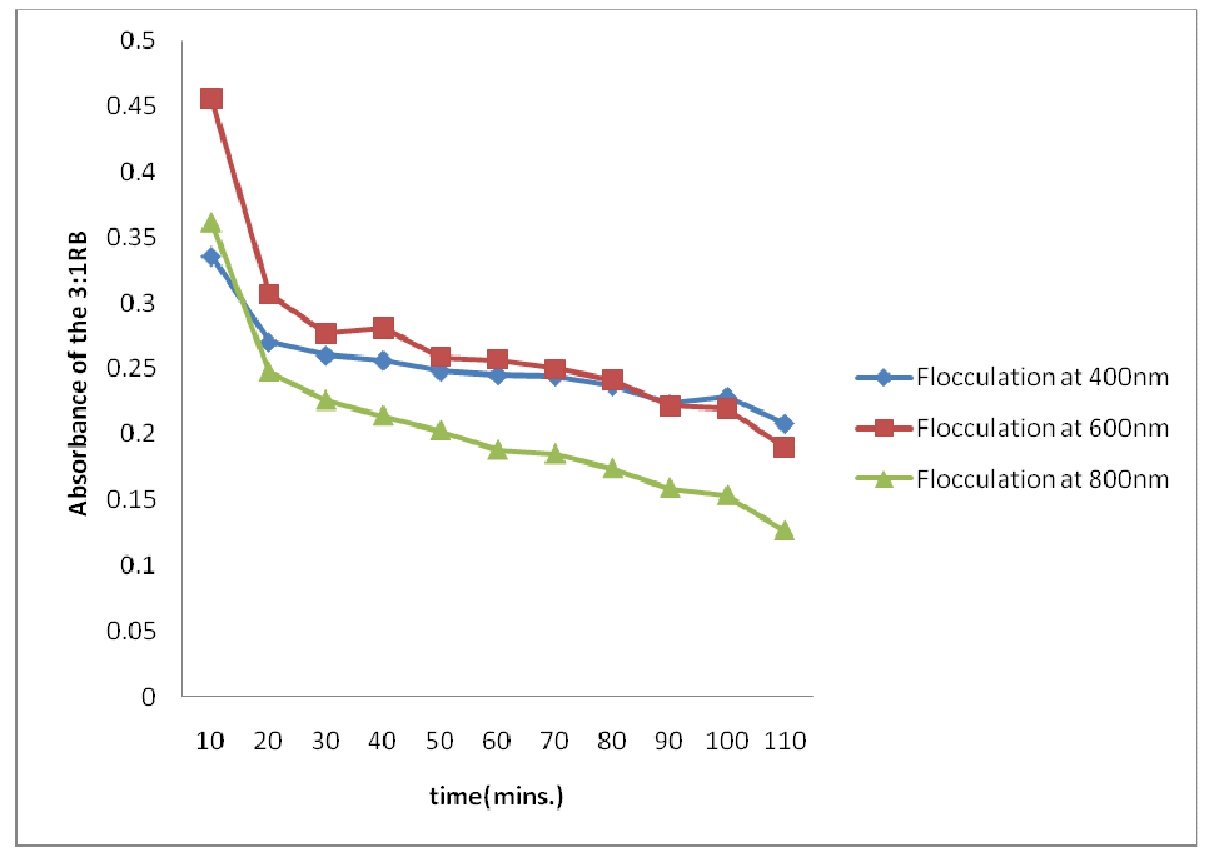

Figure 6: Flocculation profiles of the 3:1 RB at Different Wavelengths. 


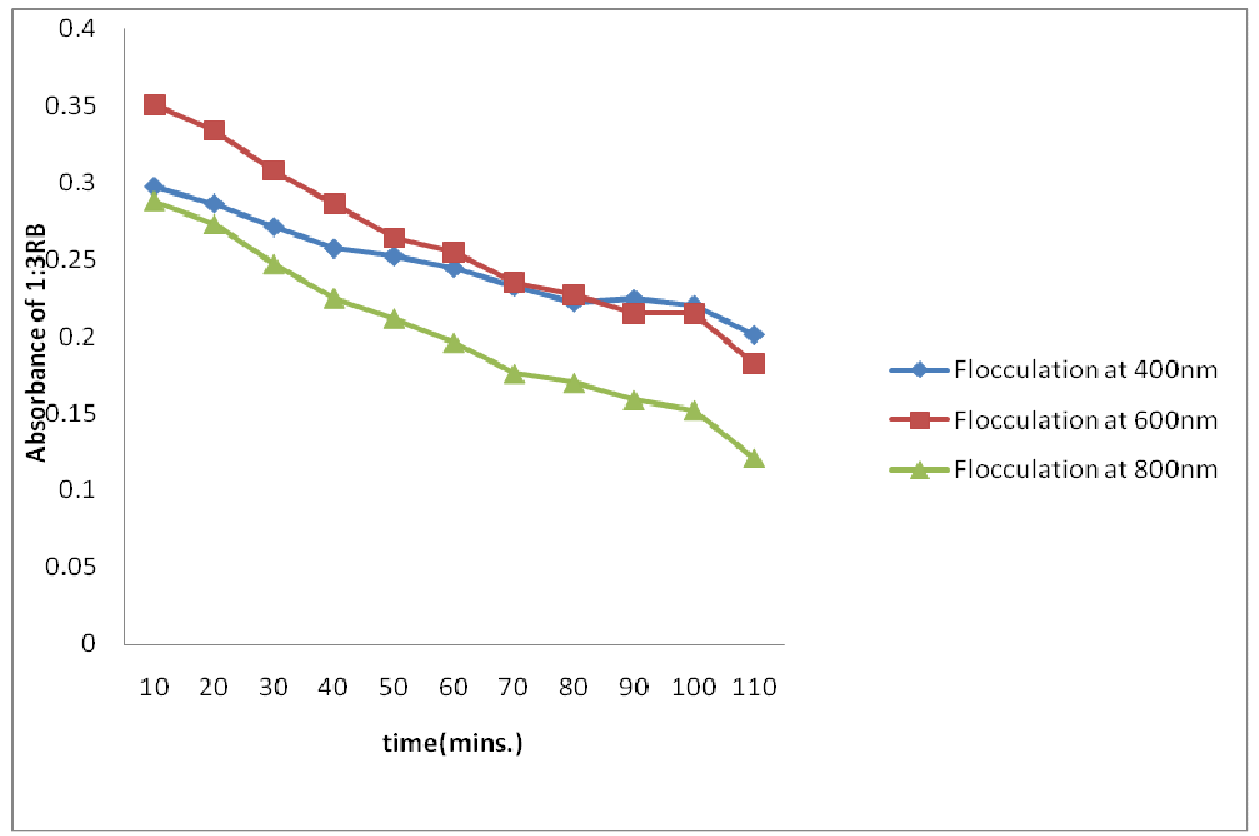

Figure 7: Flocculation profiles of the 1:3 Reactive blend.

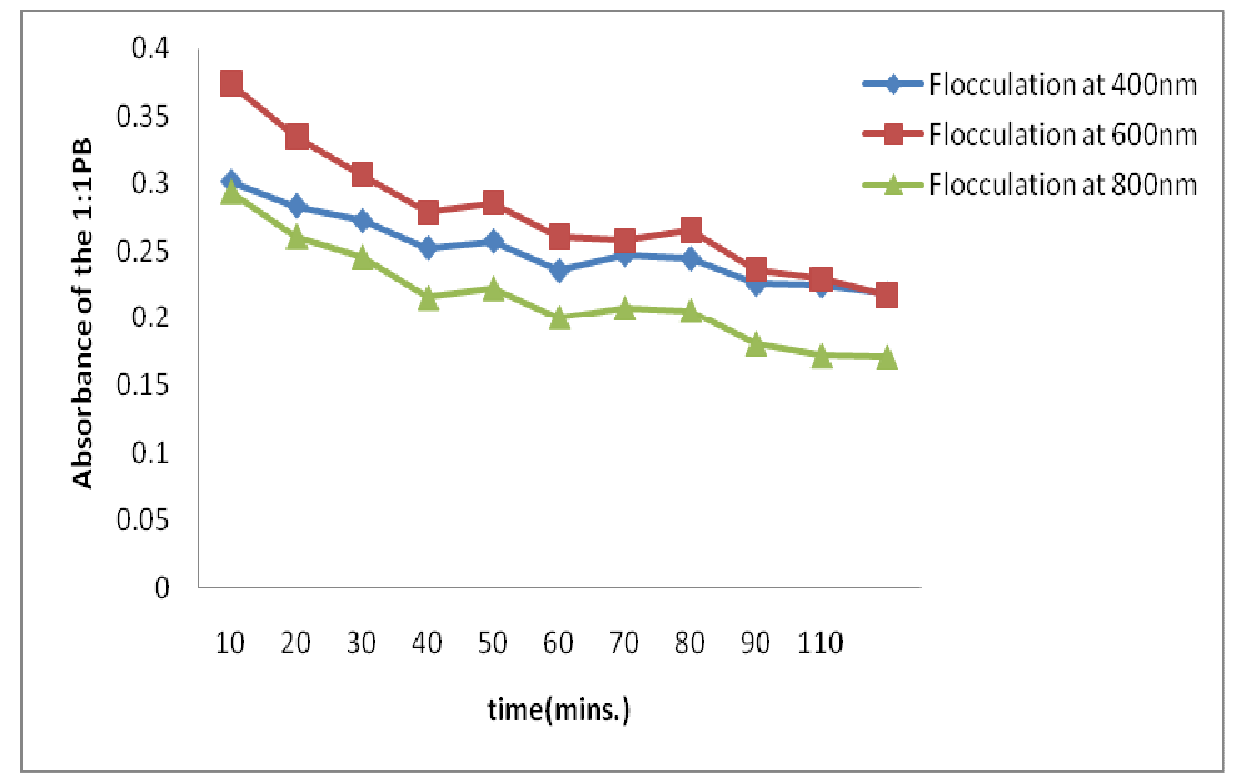

Figure 8: Flocculation profiles for the 1:1 Physical blend. 


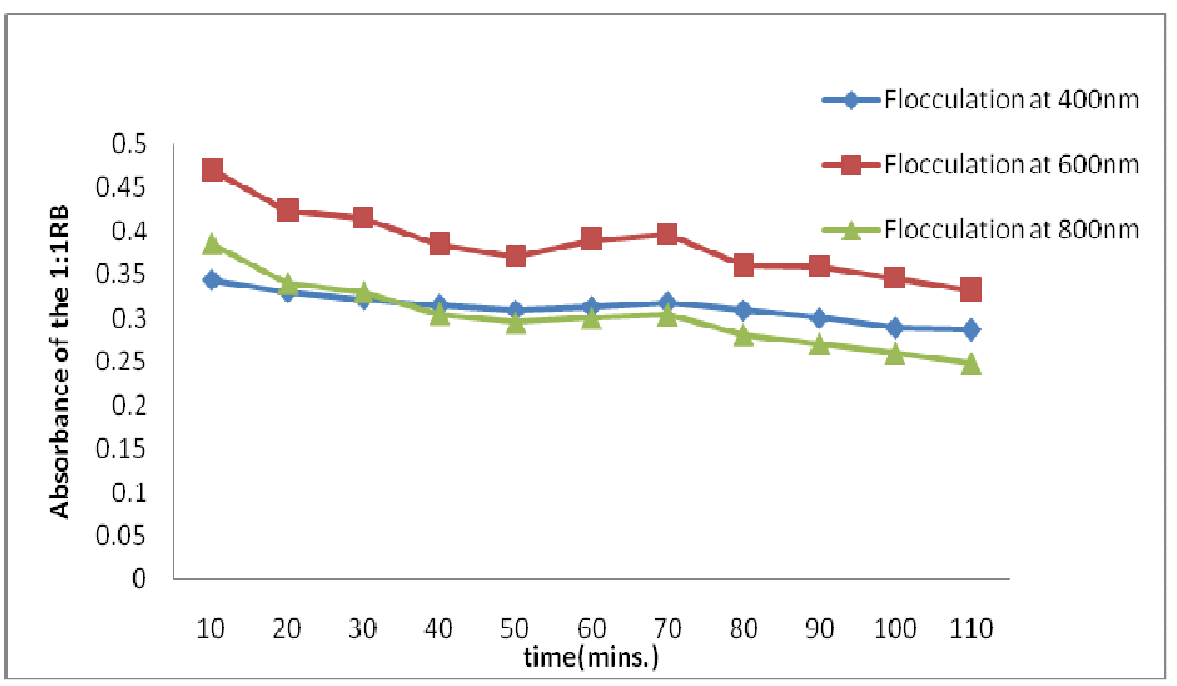

Figure 9: Flocculation profiles for the1:1 Reactive blend.

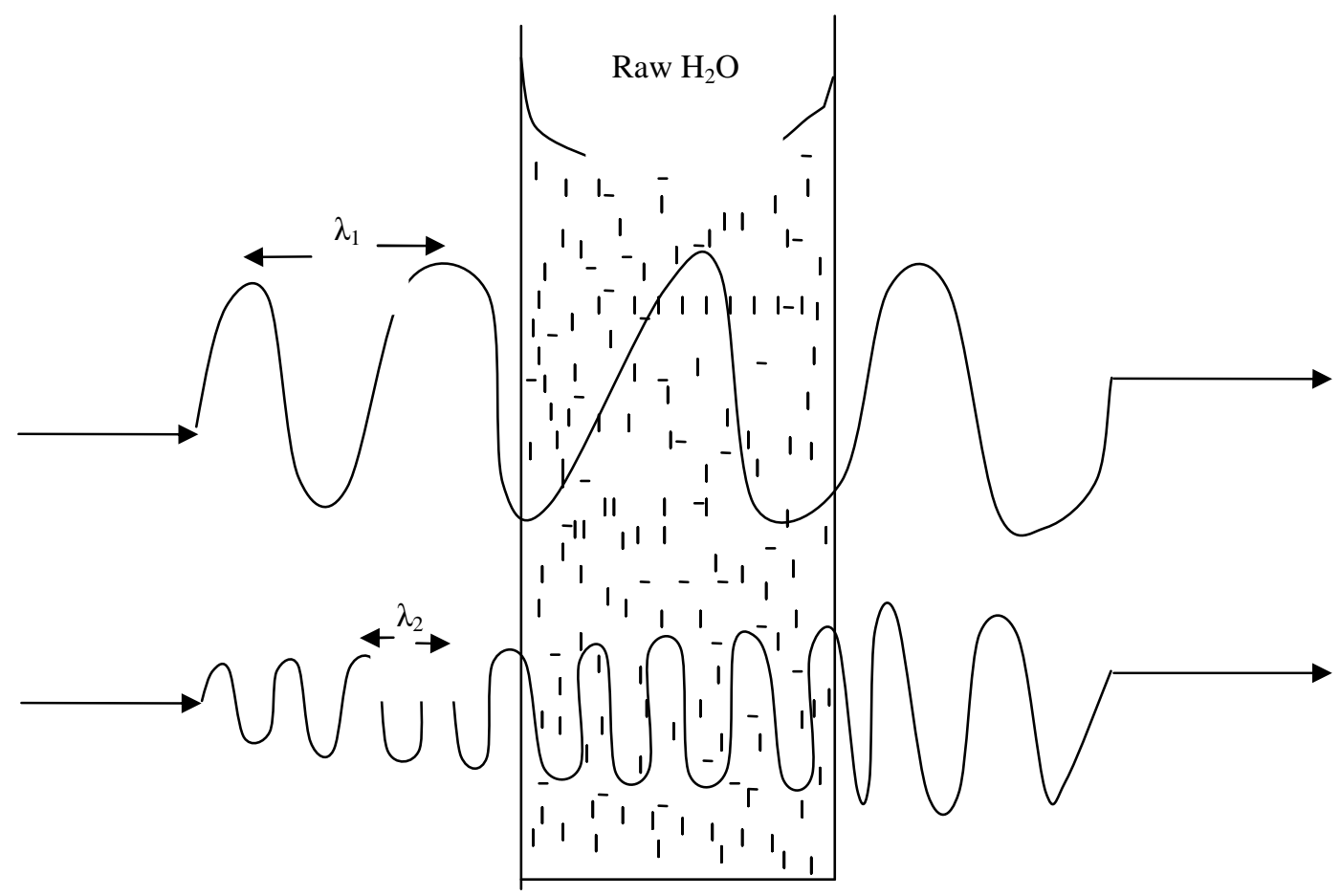

Figure 10: Schematic illustration of the effect of wavelength on flocculation efficiency. 


\section{Flocculation efficiency of Moringa oleifera}

From the results displayed in Table 2, Moringa oleifera tops the chart as the best flocculant to the tune of $89.76 \%$ after 2.5 hours of flocculation time and when flocculation was extended to 24 hours, the flocculation efficiency increased to $99.61 \%$. This result is in agreement with literature values reported for Moringa oleifera stipulating that solids removal is above $90 \%$ (Sutherland et al., 1994). Figure 4 is a graphical representation of the flocculation profile of Moringa oleifera at different wavelengths.

\section{Flocculation efficiency GA - g - PAAM}

The second best flocculant in this research was the grafted copolymeric product (GA-g-PAAM) which after 2.5 hours gave flocculation efficiencies of $44.56 \%, 55.53 \%$ and $80.38 \%$ at wavelengths of 400,600 and $800 \mathrm{~nm}$ respectively. After 24 hours, the flocculation efficiencies improved remarkably to $76.19 \%, 89.22 \%$ and $94.30 \%$ at wavelengths of 400, 600 and $800 \mathrm{~nm}$ in that order. The above results showed that the grafted product flocculates better at longer flocculation times and at longer wavelengths of ultraviolet radiation. Figure 5 is a graphical representation of the flocculation properties of GA-g-PAAM.

\section{Flocculation efficiency of M.O \&GA-g- PAAM (3:1) reactive blend}

The third most effective flocculant was the 3:1 reactive blend. After 2.5 hours of flocculation, efficiencies realized were $38.10 \%, 58.33 \%$ and $64.92 \%$ at 400,600 and $800 \mathrm{~nm}$ respectively. The efficiencies improved significantly after 24 hours giving efficiencies of $84.52 \%, 89.47 \%$ and $91.16 \%$ at wavelengths of 400, 600 and $800 \mathrm{~nm}$. Figure 6 is a graphically illustrates the flocculation properties of the 3:1 reactive blend. From the results, the products flocculate better at longer wavelengths and at longer flocculation times.
The relative high efficiency of the product may be attributed to the higher proportion of M. oleifera in the blend.

The flocculation efficiencies of MO \& GA-g-PAAM 1:3 reactive blend, MO \& GAg-PAAM 1:1 physical blend and MO \& GAg-PAAM 1:1 reactive blend generally followed the same trend of low efficiencies at shorter wavelengths and shorter flocculation times and improved efficiencies at longer wavelengths and longer flocculation times as depicted in figures 7, 8 and 9 respectively.

\section{Effect of time on flocculation efficiency}

Results from the flocculation tests carried out showed that flocculation efficiency improved considerably when interaction time of the flocculants and impurities in the raw waters was extended. According to Gerard and John (1987), supernatant clarification of raw waters is done in two steps. The first step involves the formation of stable flocs through electrostatic interactions and other flocculation mechanisms while the second step has to do with the gravitational settlement of the flocs with attendant supernatant clarification. Hence it thought that, the more time allocated for the requisite electrostatic interactions to proceed, the more stable flocs are formed. Also the longer the time, the greater the amount of flocs that settle by gravity including lighter ones and the more clarified the water becomes leading to low absorption of incident UV radiation. Hence flocculation efficiency increases with longer reaction and sedimentation times. The effect of time on either chemical or physical reactions is in conformity with contempoary works in industrial chemistry such as the work of Alamu et al. (2007).

\section{Effect of wavelength on flocculation efficiency}

Flocculation efficiency was also found to vary with wavelength of UV radiation used. The flocculation efficiencies were higher at 
longer wavelengths and vice versa. There are two possible explanations that can be proffered to the observed difference in flocculation efficiencies at different wavelengths of UV radiation. The first is in terms of wavelength while the second is in terms of energy of UV radiation used. Recall, Absorbance $A=\log \left(\frac{I_{o}}{I}\right)$ where $\mathrm{I}_{\mathrm{o}}$ and $\mathrm{I}$ are the incident and transmitted intensities of UV radiation respectively. Consider Figure 10, depicting a sample of raw water through which two incident light rays of same intensity but different wavelengths are passed.

Ray one $\left(R_{1}\right)$ and ray two $\left(R_{2}\right)$ have same intensities $\left(I_{0}\right)$ but different wavelengths $\left(\lambda_{1} \& \lambda_{2}\right)$ and $\lambda_{1}$ is longer than $\lambda_{2}$. When light is shone through the system, it is partly absorbed, scattered and reflected such that the transmitted intensity (I) is usually less than the incident intensity $\left(I_{0}\right)$ (Ogugbuaja, 2000). The absorbance of the system is thus calculated from the ratio of the transmitted intensity to the incident intensity and subsequently, flocculation efficiency. At longer wavelengths as is the case with $\mathrm{R}_{1}$, the light makes little interaction with particles in the medium and thus the incident intensity $\left(I_{0}\right)$ is slightly attenuated to give the transmitted intensity (I), a situation which leads to low absorbance and high flocculation efficiency. The understanding here may be that at longer wavelengths, an exaggerated impression of medium evacuation is given when the medium might not be as clarified as indicated. On the contrary, at shorter wavelengths of UV radiation, there is a greater propensity of the incident light $\left(\mathrm{I}_{\mathrm{o}}\right)$ interacting with particles in the medium (Figure 10) resulting to a greater attenuation of the incident light intensity and a consequent greater reduction in the transmitted light intensity (I). When this happens, the absorbance becomes higher than for longer wavelengths and thus flocculation efficiency decreases. Also, recall that the energy of the wave is given by: $E=h \frac{c}{\lambda}$; where $\mathrm{h}$ is the Plank constant, $\lambda$ is the wavelength and $\mathrm{c}$ is the velocity of light. The energy of the wave is therefore inversely proportional to the wavelength of UV radiation. At longer wavelengths, the energy of the wave is weak and it thus makes fewer collisions with particles in the medium. Consequently the radiation undergoes little attenuation leading to low absorbance and high flocculation efficiency. But at shorter wavelengths, the UV radiation is more energetic and so makes more frequent collisions with colloidal particles in the raw water and thus registers increased absorbance with attendant low flocculation efficiency. As a conclusion, we are saying that absorbance values taken at short wavelengths are likely to paint a better picture of the medium's turbidity. Therefore polymeric flocculants which give high flocculation efficiencies at shorter wavelengths are likely to be more trustworthy and merit further research into them. These include Moringa oleifera, GA-gPAAM, the $3: 1$ and the 1:3 reactive blends.

\section{Conclusion}

In this research, a graft copolymer was synthesized using gum arabic and polyacrylamide and then blended with Moringa oleifera successfully. The unblended, blended products and also Moringa oleifera were used to clarify turbid waters. The flocculation tests showed that all the products possessed laudable flocculation efficiencies with Moringa oleifera topping the chart as the best flocculant followed by the unblended product. The results therefore elucidate the advantage of synergy when materials with varying properties are integrated or blended to give a hybrid product. Consequently the foul odor sometimes 
experienced with the use of Moringa oleifera alone to treat water is eliminated when MO is blended with GA-g-PAAM. This research has brought to the lime light a water treatment chemical which has many advantages over the conventional coagulants like alum in that, its sludge is biodegradable by virtue of its organic or polysaccharide component and can be used to treat domestic water, wastewater and also industrial effluents. This water treatment chemical is therefore non noxious to the environment.

\section{REFERENCES}

Abdulkarim SM, Long K, Lai OM, Muhammad SKS, Ghazali HM. 2004. Some physic-chemical properties of Moringa oleifera seed oil extracted using solvent and aqueous enzymatic methods. Food Chemistry, 93: 253 - 263.

Ahmad AL, Wong SS, Teng TT, Zuhairi A. 2007. Improvement of Alum and $\mathrm{PACl}$ coagulation by polyacrylamides (PAMs) for the treatment of pulp and paper mill wastewater. Chemical Engineering Journal, 137: 510 - 517.

Alamu OJ, Waheed MA, Jekayinfa SO. 2007. Biodiesel production from Nigerian palm kernel oil: effect of $\mathrm{KOH}$ concentration on yield. Energy for Sustainable Development, 11(3): 77-82.

Dibenedetto A. 2011. The potential of aquatic biomass for $\mathrm{CO}_{2}$-enhanced fixation and energy production. Greenhouse Gases: Science and Technology, 1: 58-71.

Gerard RR, John MR. 1987. Flocculation. In Encyclopedia of Polymer Science and Engineering (2nd edn). John Wiley and Sons: New York; $211-233$.

Hamma'adama MA. 2005. Effect of methylolation of on dye exhaustion and dye fiber bond stability. M. Tech. Thesis, Federal University of Technology, Yola pp 43.
Hocking MB, Keith AK, Stephen L. 2002. Water soluble acrylamide copolymers. X. Flocculation Efficiencies of poly[acrylamide - co - N, N - dimethylacrylamide], polylacrylamide-comethacrylamide], Poly[acrylamide-co-Nt-butylacrylamide], and their cationic derivatives. Journal of Applied Poly Science, 84: 2090 - 2108.

Lilliehöök H. 2005. Use of sand filtration on river water flocculated with Moringa oleifera. Master thesis, Lulea University of Technology, pp. 1 - 5

Morrison RT, Boyd RN. 2007. Organic Chemistry ( $6^{\text {th }}$ edition). Pearson Education Inc. and Dorling Kindersely publishing Inc: $1113-1136$.

Ogbeifun DE, Okieimen FE. 2004. Synthesis, characterization and flocculation properties of carboxy-methyl cellulose-gAcrylamide. Journal of Sciences, 15(1): $53-57$.

Ogugbuaja VO. 2000. Absorption and Emission Spectroscopy. An Instrumental Methodology in Analytical Chemistry. Published by the Faculty of Science, University of Maiduguri, pp. 13 - 26.

Osemeahon SA, Barminas JT, Aliyu BA, Maina HM. 2007. Preliminary evaluation on the application of grafted membranes for sorption of lead and copper ion in aqueous solutions. International Journal of Physical Sciences, 2(11): 294 - 299.

Osemeahon SA, Barminas JT, Aliyu BA, Nkafamiya II. 2008. Application of grafted membranes for sorption of $\mathrm{Cd} 2+, \quad \mathrm{Fe} 2+$ and $\mathrm{Zn} 2+$ in aqueous solution. African Journal of Pure and Applied Chemistry, 2(3): 32 - 36.

Raju GB, Karuppiah MT, Latha SS, Parvathy S, Prabhakar S. 2008. Treatment of wastewater from synthetic textile industry by electrocoagulation - electrooxidation. Chemical Engineering Journal, 144: 5158. 
Romeo LM, Catalina D, Lisbona P, Lara Y, Martínez A. 2011. Reduction of greenhouse gas emissions by integration of cement plants, power plants, and $\mathrm{CO}_{2}$ capture systems. Greenhouse Gases: Science and Technology, 1: 72-82.

Schwarz D. 2000. Water clarification using Mornga oleifera. Gate Technical Information WIE GTZ; 1-7.

Sutherland JP, Folkard GK, Mtawali MA, Grant WD. 1994. Moringer oleifera as a natural coagulant. $20^{\text {th }}$ WEDC Conference on Affordable Water Supply and Sanitation. University of Leicester, UK, pp. $297-298$.
Tripathy T, Singh RP. 2001. Characterization of polyacrylamide - grafted - sodium alginate; a novel polymeric flocculants. Journal of Applied Polymer Science, 81: 3296 - 3308.

Underwood DR, Cheetham PSJ. 1994. The isolation of active emulsifier components by the fractionation of gum talha. Journal of Science, Food and Agriculture, 66: 217-224.

Willey JM, Sherwood LM, Woolverton CJ. 2008. Prescott, Harley and Klein's Microbiology ( $7^{\text {th }}$ edition). McGraw-Hill Companies Inc.: New York; 1050 - 1086. 